\title{
The way to a man's heart is through his stomach
}

\section{A curious case of myopericarditis associated with Campylobacter enteritis}

Alexander Elford, Harsh Thakkar, Paul Maclntyre

CASE

A man aged 29 years presented to a general practitioner with mild central chest pain and non-bloody diarrhoea. Two days before presentation, he developed symptoms after consuming undercooked meat at a barbeque. $\mathrm{He}$ described subjective fevers and chills with central, constant, pleuritic chest pain that radiated down both arms and was worse when leaning forward. He was a non-smoker with a history of pericarditis six years prior. His vital signs were heart rate 99 beats/min and regular, blood pressure $140 / 90 \mathrm{mmHg}$, respiratory rate 14 breaths/min and temperature $37.5^{\circ} \mathrm{C}$. Physical examination, including the cardiovascular system, was normal. As his electrocardiogram (ECG; Figure 1) was noted to be abnormal, he was transferred to the emergency department by ambulance for further assessment.

\section{QUESTION 1}

What does the patient's ECG show?

\section{QUESTION 2}

What are your differential diagnoses? What investigations would you order next?

\section{ANSWER 1}

The ECG demonstrates $1 \mathrm{~mm}$ concave upward ST elevation in leads V3-V6 and PR depression in leads I, II and aVF. Importantly, the ST changes are not in a single coronary artery distribution. There is an absence of reciprocal changes, differentiating it from an acute myocardial infarction.

\section{ANSWER 2}

Differential diagnoses include:

- acute coronary syndrome

- pericarditis

- myopericarditis.

This patient should be referred for further work-up in an acute care setting, ideally with an onsite cardiology service. Investigations would include:

- serial troponins and ECGs to monitor for dynamic changes to assess for acute coronary syndrome

- telemetry to monitor for arrhythmias

- full blood examination and C-reactive protein to assess for an infectious or inflammatory cause

- autoimmune screen (antinuclear antibodies, extractable nuclear antigens, dsDNA and rheumatoid factor) to rule out autoimmune disease, given the history of pericarditis six years ago

- chest X-ray

- urea, electrolytes and creatinine

- stool polymerase chain reaction (PCR) and stool microscopy, culture and sensitivity.

\section{CASE CONTINUED}

Serial ECGs were similar and without dynamic changes. Serial troponin-Ts were $206 \mathrm{ng} / \mathrm{L}$ and $229 \mathrm{ng} / \mathrm{L}$. C-reactive protein was $144.7 \mathrm{mg} / \mathrm{L}$. The autoimmune screen was negative.

QUESTION 3

What is the most likely diagnosis and how would you proceed?

ANSWER 3

The most likely diagnosis is myopericarditis. The concave ST segment elevation and depressed PR segments are classic signs of pericarditis. ${ }^{1}$ The lack of dynamic and reciprocal changes make acute coronary syndrome unlikely. The elevated troponins indicate myocardial involvement. It is recommended that patients with myopericarditis be admitted for monitoring and treated with non-steroidal anti-inflammatory drugs and colchicine. An echocardiogram should be arranged to assess for systolic function and presence of pericardial effusion. Cardiac magnetic resonance imaging can be considered as it is also sensitive for myocarditis and gives additional information to an echocardiogram.

\section{CASE CONTINUED}

The patient's stool PCR was positive for Campylobacter spp. DNA. The stool microscopy, culture and sensitivity grew Campylobacter jejuni.

His echocardiogram demonstrated normal ventricular function and the 
absence of a pericardial effusion. No arrythmias were noted on his telemetry.

\section{QUESTION 4}

Are Campylobacter spp. the cause of the patient's myopericarditis?

\section{QUESTION 5}

How do the echocardiogram findings affect your management plan?

\section{QUESTION 6}

Is there any specific treatment required for Campylobacter spp.-associated cardiac disease? What is the prognosis?

\section{ANSWER 4}

Given the autoimmune screen was negative, it was postulated that this presentation was more likely secondary to an acute Campylobacter enteritis infection. There have been no symptoms or systemic manifestations of autoimmune disease since the presentation of pericarditis six years ago, which makes a systemic disease less likely. Campylobacter spp. infection is the most common cause of bacterial enteritis in developed countries, often related to undercooked meats or unpasteurised milk. ${ }^{2}$ The condition normally resolves with conservative treatment. However, in rare cases of Campylobacter spp. infection, there is an association with cardiac complications. A literature review published in 2016 identified 44 published cases of pericarditis, myocarditis, myopericarditis or perimyocarditis associated with Campylobacter spp. infection. ${ }^{3}$ The typical population affected is young men. It is unclear whether the cardiac involvement is due to an immunologic phenomenon, as in GuillainBarré syndrome-related Campylobacter spp. infection, or a direct effect of Campylobacter spp. on the myocytes. ${ }^{4}$

\section{ANSWER 5}

Given the echocardiogram findings were normal, treating the inflammation without adjunct treatments is appropriate. If there were a reduced ejection fraction, addition of angiotensin converting enzyme (ACE) inhibitors and a $\beta$-blocker would be beneficial to aid myocardial recovery. ${ }^{5}$ Detection of a moderate or large pericardial effusion would need careful inpatient monitoring, repeat imaging as well as consideration of a pericardiocentesis pending the patient's clinical status. Echocardiography may
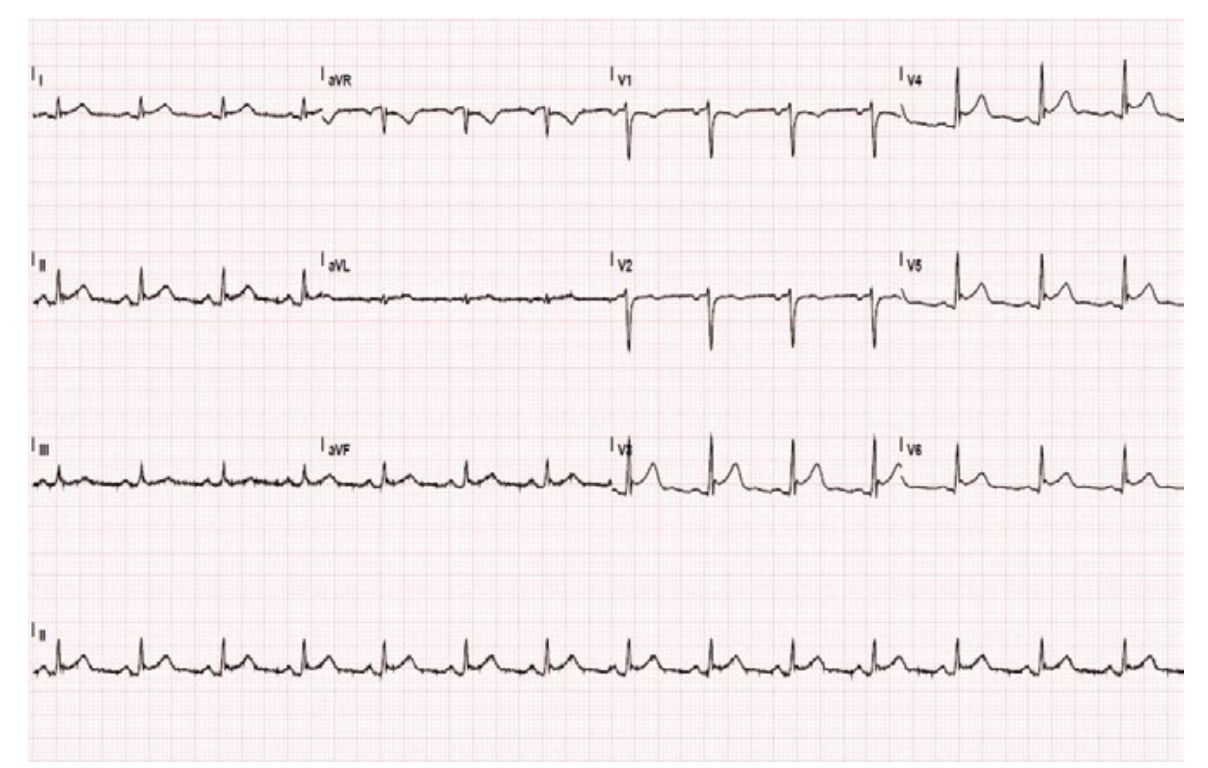

Figure 1. Electrocardiogram taken during chest pain

Authors

Alexander Elford MBBS, Medical Registrar, Royal Hobart Hospital, Tas

Harsh Thakkar MBBS, Cardiology Advanced Trainee, Royal Hobart Hospital, Tas 
Paul Maclntyre MBChB, BSc, MSc, MD, FRCP(UK),

FRACP, Director of Acute Medical Services and

Director of Cardiology, Royal Hobart Hospital, Tas;

Consultant Cardiologist, Hobart Private Hospital, Tas

Competing interests: None.

Funding: None.

Provenance and peer review: Not commissioned externally peer reviewed.

\section{Correspondence to:}

alexelford@live.com

\section{References}

1. Imazio M, Trinchero R. Myopericarditis: Etiology, management, and prognosis. Int J Cardiol 2008;127(1):17-26. doi: 10.1016/j.ijcard.2007.10.053.

2. Hannu T, Mattila L, Rautelin H, Siitonen A, Leirisalo-Repo M. Three cases of cardiac complications associated with Campylobacter jejuni infection and review of the literature. Eur J Clin Microbiol Infect Dis 2005;24(9):619-22. doi: 10.1007/s10096-005-0001-2.

3. Hessulf $F$, Ljungberg J, Johansson P, Lindgren $M$, Engdahl J. Campylobacter jejuni-associated perimyocarditis: Two case reports and review of the literature. BMC Infect Dis 2016;16(1):289. doi: 10.1186/s12879-016-1635-7.

4. Greenfield G, Mailey J, Lyons K, Trouton T. Acute myocarditis secondary to acute Campylobacter jejuni infection. Clin Med (Lond) 2018;18(1):98-99. doi: 10.7861/clinmedicine.18-1-98.

5. Caforio A, Pankuweit S, Arbustini E, et al. Current state of knowledge on aetiology, diagnosis, management, and therapy of myocarditis: A position statement of the European Society of Cardiology Working Group on Myocardial and Pericardial Diseases. Eur Heart J 2013;34(33):26-48. doi: 10.1093/eurheartj/eht210. 